\title{
EEG findings in chlor-alkali workers subjected to low long term exposure to mercury vapour
}

\author{
LEENA PIIKIVI, ${ }^{\prime}$ U TOLONEN ${ }^{2}$ \\ From the Oulu Health Centre,' Division of Occupational Health, SF-90101 Oulu, and Department of \\ Neurology, ${ }^{2}$ Oulu University Central Hospital, SF-90220 Oulu, Finland
}

ABSTRACT The cerebral effect of long term (mean 15.6, SD 8.9 years) and low (about $2.5 \mu \mathrm{g} / \mathrm{m}^{3}$ air

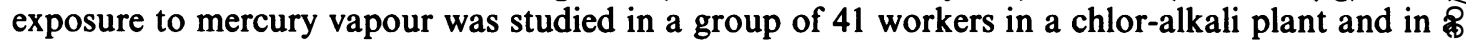
group of matched referents by electroencephalography (EEG). In the visually interpreted EEGs onl a tendency for an increased number of EEG abnormalities, especially focal ones, could be seen in thọ exposed subjects. In the computerised EEG (cEEG), however, the exposed workers had significantl\% slower and more attenuated EEGs than the referants. This difference was most prominent in the occipital region, became milder parietally, and was almost absent frontally. Our results suggest tha cEEG may show early effects on the brain of exposure to mercury vapour.

Symptoms from the central nervous system such as weakened memory, insomnia, dizziness, and tremor have been early findings in workers excessively exposed to metallic mercury $(\mathrm{Hg})$ vapour. ${ }^{2}$ In chronic poisoning caused by $\mathrm{Hg}$ vapour diffuse slowing of electroencephalograms (EEG) has been shown in five of nine patients by Vroom and Greer. ${ }^{3}$ Furthermore, toxic effects of $\mathrm{Hg}$ on the EEG have been described as bradyrhythmia or diffuse changes. ${ }^{45}$ So far as we know, no computerised EEG (cEEG) studies showing the effects of exposure to $\mathrm{Hg}$ vapour have been published, even though the method has been frequently applied in pharmaceutical research. ${ }^{6}$

The purpose of our study was to discover whether EEG, and especially cEEG, could show cerebral effects caused by long term low exposure to $\mathrm{Hg}$ vapour.This was indeed the case; we found slowing and attenuation of EEG especially in the occipital area of the brain.

\section{Subjects and methods}

STUDY GROUP AND STUDY DESIGN

The study had a cross sectional design in which the data from exposed subjects were compared with the data of their matched referents. The indicator of the long term $\mathrm{Hg}$ exposure was calculated from the retrospectively collected results of the blood $\mathbf{H g}$ analyses.
The exposed group consisted of 41 men from chlor-alkali plant with an exposure time of at least five years. Their mean age was $38 \cdot 1$ (SD 6.7, range 28-56 years. The exposure time varied from five to 27 years (mean 15.6, SD 8.9). Subjects with neurologica psychiatric, and metabolic diseases, skull injurieso hypertension, and a history of mercury intoxication were excluded on the basis of previous documents of periodical health examinations performed twice a yea as well as of possible case records. Five chlor-alka workers were excluded from the study, three wit hypertension medicated by beta-blockers and two with periodical excessive use of alcohol. One subgroug $(\mathrm{n}=21)$ had regular daywork. The second subgroup $(n=20)$ had varying three-shift work with periods of four workshifts and two rest days.

One referent, matched for age ( \pm 1 year) and sex was chosen for every exposed subject. The 41 referento were employed in mechanical wood processing plants? Exclusion criteria from the reference group were earlier occupational exposure either to heavy metals wood conserving chemicals, or solvents and a history of the diseases or injuries listed above. Rejection from the referent group was based on medical records and on the judgment of the occupational health staff of the employing company. The mean age of the referents was $38 \cdot 1$ (SD 6.6, range 28-55) years. All referents ha regular daywork.

EXAMINATIONS

The subjects came at 1300 from their workplaces $t \stackrel{8}{8}$ Oulu University Central Hospital where the examina苂 
tions took place. The dayshift workers and referents had had five and the exposed three-shift workers six working hours before their arrival. Only one subject was examined a day. Special attention was given to standardisation of timing and to the strict procedure of the examinations.

At the beginning of the examination every subject was interviewed according to a fixed schedule where previous medical and occupational history, actual health status, and life style were investigated. The interview was followed by a routine clinical examination and a computer administered psychological test battery. After a short rest the examination continued with measurements in the laboratory of clinical neurophysiology. The subjects did not smoke or take coffee during the three hours preceding the EEG recording. Based on the interviews and the observations from the routine clinical examinations, the health state of all the workers was judged to be good. The subjects did not report actual use of any medicines possibly affecting the central nervous system and they had not consumed more alcohol than two bottles of beer $(=0.71)$ the previous evening.

\section{EXPOSURE DATA}

The time weighted average concentration of $\mathrm{Hg}$ in blood (the TWA B Hg) was computed as an indicator of long term exposure. Measurements of $\mathrm{B} \mathrm{Hg}$ covered the period from 1969 until the study. Since 1974 B Hg had been monitored with the cold vapour atomic absorption method of Magos and Cernik ${ }^{7}$ modified by Lajunen et al. ${ }^{8}$ Both the inorganic and organic fractions of $\mathrm{Hg}$ could be detected by this method.

The dose indicators of the actual exposure of the study group were inorganic $\mathrm{B} \mathrm{Hg}$ (io $\mathrm{B} \mathrm{Hg}$ ), organic $\mathrm{B}$ $\mathrm{Hg}$ (o B Hg), total B $\mathrm{Hg}(\mathrm{B} \mathrm{Hg})$, and urinary $\mathrm{Hg}$ (U $\mathrm{Hg})$. A venous blood sample $(25 \mathrm{ml})$ was taken during the hospital examination. Morning urine samples collected at home on the morning of the examination day were used for $\mathrm{U} \mathrm{Hg}$ analyses. The polyethylene blood tubes (containing $0.15 \mathrm{ml}$ Heparin Medica $5000 \mathrm{U} / \mathrm{ml}$, Finland) and the urine bottles had been checked for lack of $\mathrm{Hg}$ contamination. The modification of Magos and Cernik was applied in analyses of actual $\mathrm{Hg}$ concentrations in both blood and urine. The $\mathrm{Hg}$ concentration in urine was corrected for a urinary creatinine concentration of $1 \mathrm{mmol} / 1$ according to Jaffe's standard method. ${ }^{9}$

\section{CHARACTERISTICS OF THE STUDY GROUP}

The individual TWA B Hg concentrations were based on the average of 22 (SD 5.7, range 9-32) measurements. The mean TWA B Hg of the exposed group was $59 \cdot 0$ (SD 12.6, range 40.7-90.0) nmol/l. The mean TWA of inorganic B $\mathbf{~ H g}$ for the group was 34.9 (SD 12.6, range 17.7-58.5) $\mathrm{nmol} / \mathrm{l}$. In nine exposed subjects the TWA organic $\mathrm{B} \mathrm{Hg}$ concentration exceeded the concentration of the TWA inorganic B $\mathrm{Hg}$.

Table 1 shows the figures of the indicators of actual exposure. For three of the exposed, the organic $\mathrm{B} \mathrm{Hg}$ was higher than the inorganic fraction. Among the exposed workers the mean concentrations of $\mathrm{Hg}$ in blood and urine were rather low compared with earlier published results-for instance, by Skerfving and Berlin. ${ }^{10}$ None of the referents had more inorganic than organic $\mathrm{Hg}$ in their blood. The blood and urinary $\mathrm{Hg}$ concentrations of the reference subjects were also low.

To minimise the possible confounding effect of different workshifts, the exposed three-shift workers attended examinations during their morning shift. When the exposure of the exposed day labourers and three-shift workers were compared, the exposure level of the former group was significantly higher than that of the latter group (fig 1). The TWA B Hg of the day worker group was 65.9 (SD 10.9 , range 45.7 $82.4) \mathrm{nmol} / \mathrm{l}$ and of the three-shift worker group 51.9 (SD $10 \cdot 2$, range $40 \cdot 7-90 \cdot 0) \mathrm{nmol} / \mathrm{l}$. The inorganic TWA B Hg of the day workers was also higher, 42.6 (SD 12.6, range 20.4-64.1) nmol/1, compared with the value of the three-shift workers, 26.9 (SD 6.0, range 16.9-37.0) $\mathrm{nmol} / \mathrm{l}$.

Table 1 Figures of the indicators for actual exposure of the exposed and reference groups

\begin{tabular}{|c|c|c|c|c|c|c|}
\hline \multirow[b]{2}{*}{ Indicator of exposure } & \multicolumn{3}{|c|}{ Exposed $(n=41)$} & \multicolumn{3}{|c|}{ Referents $(n=41)$} \\
\hline & Mean & $S D$ & Range & Mean & $S D$ & Range \\
\hline $\begin{array}{l}\text { io B Hg }(\mathrm{nmol} / 1) \\
\text { o B Hg }(\mathrm{nmol} / \mathrm{l}) \\
\text { B Hg }(\mathrm{nmol} / \mathrm{l}) \\
\mathrm{U} \mathrm{Hg}(\mu \mathrm{mol} / \mathrm{mol}) \mathrm{creat} \\
(\mathrm{nmol} / \mathrm{l})\end{array}$ & $\begin{array}{l}38 \cdot 8 \\
19 \cdot 1 \\
58 \cdot 0 \\
11 \cdot 6 \\
(96 \cdot 6)\end{array}$ & $\begin{array}{c}24 \cdot 5 \\
10 \cdot 8 \\
26 \cdot 5 \\
7 \cdot 4 \\
(61 \cdot 6)\end{array}$ & $\begin{array}{c}10-130 \\
10-165 \\
25-150 \\
2 \cdot 1-31 \cdot 2 \\
(20-260)\end{array}$ & $\begin{array}{c}4 \cdot 3 \\
14 \cdot 5 \\
18 \cdot 8 \\
1 \cdot 1 \\
(9 \cdot 2)\end{array}$ & $\begin{array}{c}2 \cdot 9 \\
8 \cdot 0 \\
8 \cdot 9 \\
0 \cdot 8 \\
(6 \cdot 7)\end{array}$ & $\begin{array}{l}<5-10 \\
5-40 \\
5-45 \\
0 \cdot 0-2 \cdot 9 \\
(0 \cdot 0-25)\end{array}$ \\
\hline
\end{tabular}

io $\mathrm{B} \mathrm{Hg}=$ Inorganic blood mercury.

o B Hg = Organic blood mercury.

B $\mathrm{Hg}=$ Total blood mercury.

$\mathrm{U} \mathbf{H g}=$ Urinary mercury. 


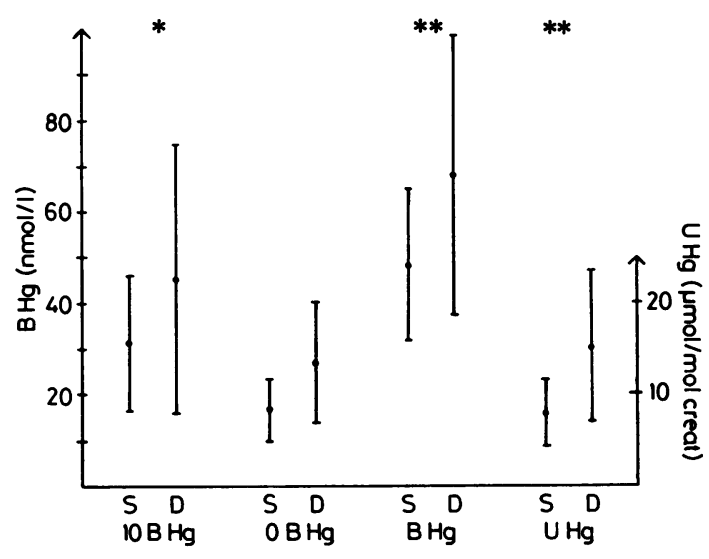

Fig 1 Means and SDS of actual dose indicators of exposed subjects grouped according to workshifts. $(S=$ three-shift workers, $n=20 ; D=$ day workers, $n=21$. io $B$ $\mathrm{Hg}=$ inorganic blood mercury; o $\mathrm{B} \mathrm{Hg}=$ organic blood mercury; $\mathbf{B} \mathbf{H g}=$ blood mercury; $\boldsymbol{U} \mathbf{H g}=$ urinary mercury. ${ }^{*} p<0.05 ;{ }^{* *} p<0.01$.

\section{RECORDING OF EEG}

The EEGs were recorded with a 16 channel electroencephalograph. During the recording the subjects lay awake with their eyes closed. Both photic stimulation $(0-40 \mathrm{~Hz})$ and hyperventilation $(3 \mathrm{~min})$ were performed within every recording. Visual interpretation of the EEGs was performed by one of the authors (UT) without knowledge as to whether the subject belonged to the exposed or reference group. The classification of the normality and abnormality was made according to the scaling presented earlier by Tolonen and Abonen. ${ }^{11}$ The scaling, including both focal, generalised and paroxysmal EEG disturbances, consisted of four classes: (i) normal, (ii) mildly disturbed, (iii) moderately disturbed, and (iv) severely disturbed.

The recording of the EEG for quantification was always performed in the same way: before each recording session the subject lay with eyes open and talked with the EEG technician to ensure that normal vigilance was maintained. Moreover, if during the recording the EEG showed signs of drowsiness, the EEG technician stimulated the subject to keep awake. For quantification the EEGs were recorded using a time constant of $0.3 \mathrm{~s}$ and a high frequency cutoff point of $70 \mathrm{~Hz}$. Only derivations $\mathrm{O}_{1}$ and $\mathrm{O}_{2}$ with eyes open and closed, $P_{3}$ and $F_{3}$ as well as $P_{4}$ and $F_{4}$ with eyes closed, all referenced to linked ears $\left(A_{1} A_{2}\right)$, were computerised. For EEG quantification of all subjects, a representative artifact free epoch of 40 (or $20+20$ ) seconds from each channel was selected without knowledge of the exposure status of the subject. The EEG quantification was performed off line (from a digital PCM tape recorder) by means of a PDP 11/23 minicomputer. The signal was low pass filtered at $31.5 \mathrm{~Hz}$ and the sampling frequency used was $100 \mathrm{HzO}$ Several power spectral parameters, including both. absolute and relative powers, with Fast Fourier Trans $\overline{\overrightarrow{\bar{\sigma}}}$ form were calculated. In addition to absolute and relative band power parameters, some othes parameters were calculated, such as mean frequency and also amplitude of the signal reflected by root mea square (RMS). The frequency bands used for calculo tions were $13.5-30 \mathrm{~Hz}$ for beta, $7 \cdot 5-13.5 \mathrm{~Hz}$ for alphaw, $3.5-7.5 \mathrm{~Hz}$ for theta, and $0.5-3.5 \mathrm{~Hz}$ for delta.

\section{Results}

\section{VISUALLY INTER PRETED EEG}

Table 2 shows the visually interpreted EEG findings for both the study groups. A greater occurrence of EEG abnormalities in the exposed $(24 \%)$ than in the referents $(15 \%)$ could be seen, but the difference was not statistically significant. Paroxysmal epileptiform? activity was detected in two, both belonging to theexposed group: one had parieto-occipital spikes on the left side and the other had a theta burst occipitally or the right side. In the exposed group focal abnor $\vec{\omega}$ malities slightly dominated over generalised disturø bances but in the reference group generalised EEG disturbances were more abundant. Focal abnoro malities were all mild and were situated in the leff hemisphere frontotemporally-temporally-temporo basally except in one subject among the expose group, the focus of whom was parieto-occipitally o⿺ the left side. Three subjects had both generalised and focal abnormalities. All EEG abnormalities excep $\bar{B}$ one were scaled as "mild." One referent showed 2 moderate EEG disturbance that appeared as a slowing. of background activity imitating poorly mature $\bar{\phi}$ EEG.

\section{QUANTITATIVE EEG}

Firstly, comparisons were made between the exposed and reference groups' power density spectra recordees from the three regions of the brain. The most sigo

Table 2 Visually interpreted EEG findings in the exposed and reference groups

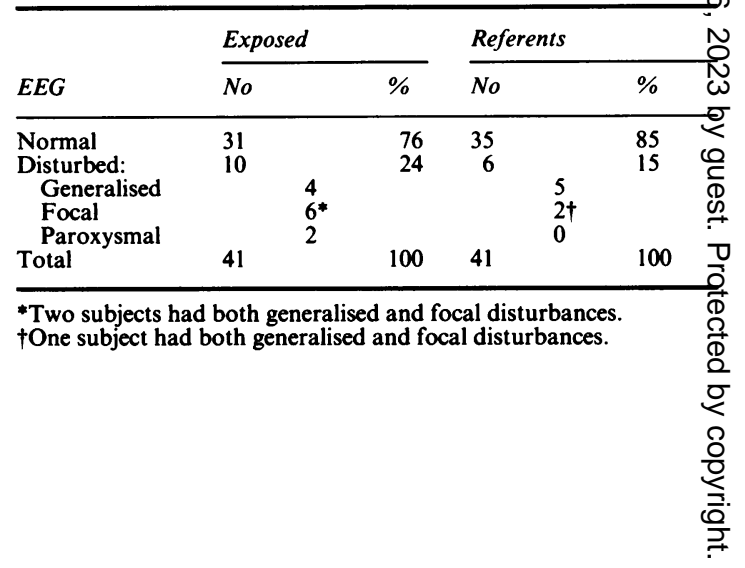



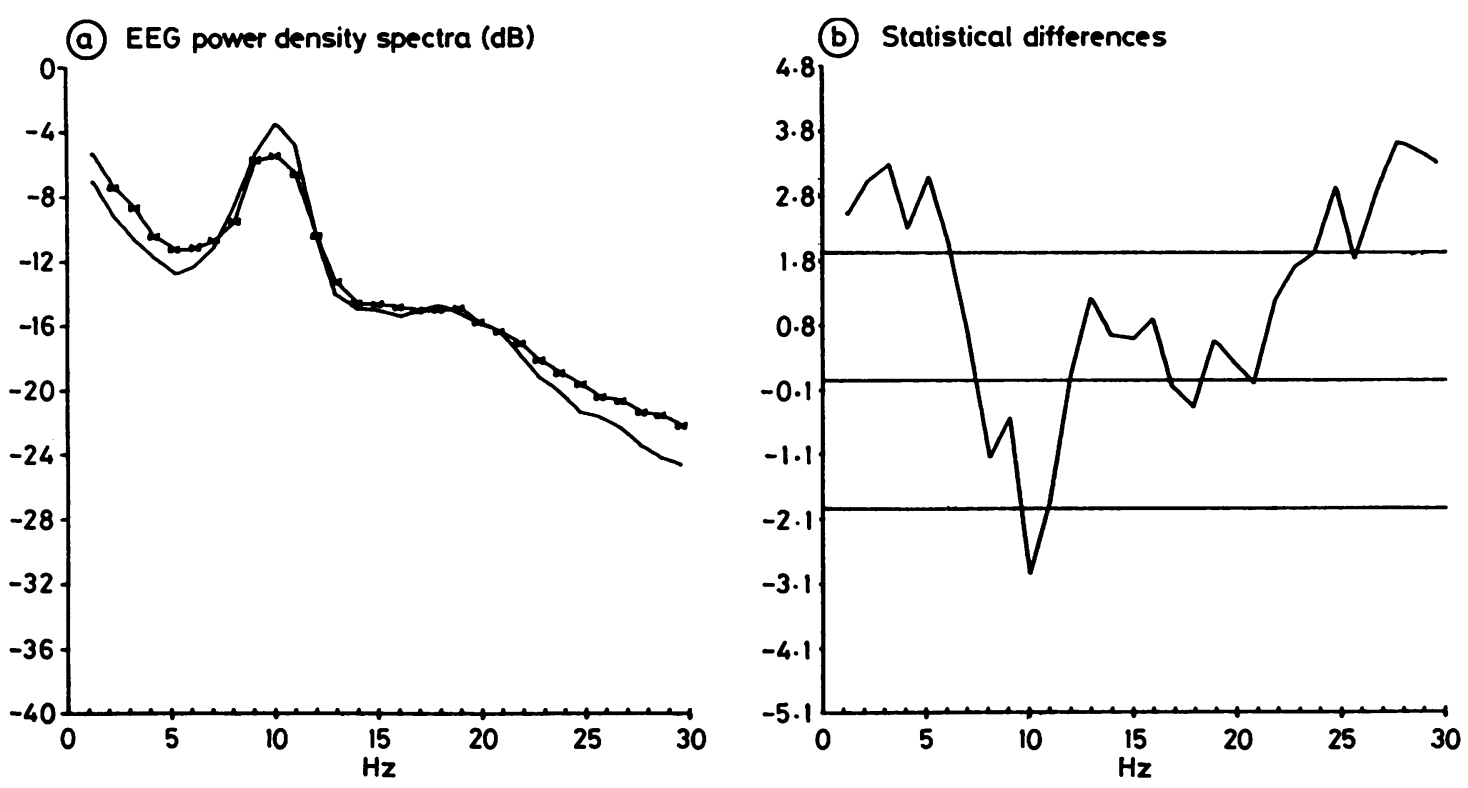

Fig 2 (a) Mean power density spectra of occipital registration $\left(O_{1}-A_{1} A_{2}\right)$ of exposed (****) and reference ( - ) groups. (b) Statistical comparison (two sided t test with Welch's correction) between exposed and reference groups' spectra.

Horizontal lines above and below zero level indicate $95 \%$ confidence interval.

nificant difference between the groups was seen occipitally (fig 2 ). The results from the right and left hemisphere were equal to each other.The difference became milder parietally and almost disappeared frontally. All the single absolute cEEG parameters shown in table 3 were lower in the exposed than in the referents. Highly significant differences $(p<0.001)$ were seen in the alpha frequency powers, total powers, and values of RMS (reflecting the amplitude of the signal) of the spectra.

Secondly, to explore the possible confounding effect of the vigilance on the cEEG of the exposed, the cEEG parameters of the exposed day workers and three-shift workers were compared with the parameters of their referents (table 4). In the dayworker group all the parameters were lower than in their referents even if a statistically significant difference was seen only in the power of alpha frequency $(\mathrm{t}-2 \cdot 2, \mathrm{p}<0.05)$. In the three-shift worker group the slowing and attenuation of the cEEG was more emphasised, the difference between all the parameters of this exposed subgroup and their referents being statistically significant. Figure 3 shows the diagrams of the statistical differences between the exposed dayworkers and their referents as well as between the exposed three-shift workers and their referents. In addition, a two way analysis of variance was applied to detect connections between workshift, dose indicators and values of the

Table 3 Absolute frequency powers, total powers, and amplitudes of the signal reflected by root mean square (RMS) in the cEEG for the exposed and reference subjects. (Two sided t test with Welch's correction, derivation $O_{1}$ referenced to linked ears, eyes closed)

\begin{tabular}{|c|c|c|c|c|c|c|}
\hline \multirow[b]{2}{*}{$E E G$ variable } & \multicolumn{2}{|c|}{ Exposed $(n=41)$} & \multicolumn{2}{|c|}{ Referents $(n=41)$} & \multirow[b]{2}{*}{$t$} & \multirow[b]{2}{*}{$p$} \\
\hline & Mean & $S D$ & Mean & $S D$ & & \\
\hline Mean frequency $(\mathrm{Hz})$ & $8 \cdot 3$ & $1 \cdot 3$ & $9 \cdot 0$ & 1.0 & $-2 \cdot 7$ & $<0.01$ \\
\hline $\begin{array}{l}\text { Frequency (pW): } \\
\text { Delta } \\
\text { Theta } \\
\text { Alpha } \\
\text { Beta }\end{array}$ & $\begin{array}{r}12.9 \\
8.7 \\
35 \cdot 6 \\
8.4\end{array}$ & $\begin{array}{r}5 \cdot 4 \\
5 \cdot 6 \\
36 \cdot 0 \\
5 \cdot 6\end{array}$ & $\begin{array}{l}16 \cdot 8 \\
14 \cdot 3 \\
90 \cdot 5 \\
16 \cdot 1\end{array}$ & $\begin{array}{r}9 \cdot 6 \\
11.9 \\
90 \cdot 2 \\
13 \cdot 1\end{array}$ & $\begin{array}{l}-2.3 \\
-2.8 \\
-3.6 \\
-3.4\end{array}$ & $\begin{array}{l}<0.05 \\
<0.01 \\
<0.001 \\
<0.01\end{array}$ \\
\hline $\begin{array}{l}\text { Total power (pW) } \\
\text { RMS }(\mu \mathrm{V})\end{array}$ & $\begin{array}{r}65.5 \\
7.7\end{array}$ & $\begin{array}{r}46 \cdot 0 \\
2 \cdot 6\end{array}$ & $\begin{array}{l}138 \\
11 \cdot 0\end{array}$ & ${ }_{4 \cdot 3}^{112}$ & $\begin{array}{l}-3.8 \\
-4.2\end{array}$ & $\begin{array}{l}<0.001 \\
<0.001\end{array}$ \\
\hline
\end{tabular}




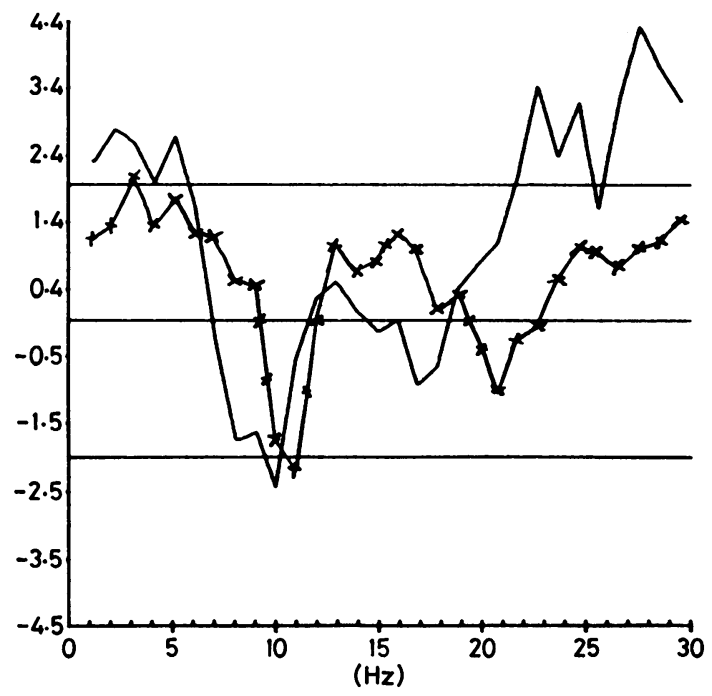

Fig 3 Statistical differences between occipital $\left(O_{1}-A_{1} A_{2}\right)$ mean power density spectra of cEEG for exposed three-shift workers and their referents (- ) and for exposed day workers and their referents (****). Horizontal lines above and below zero indicate $95 \%$ confidence interval. (Two sided t test with Welch's correction.)

alpha frequency, total power, and signal RMS. No significant relations, however, were seen (all $F$ values $<3.07, \mathrm{p}>0.09$ ).

\section{Discussion}

In our study a tendency towards increased, mainly focal disturbances was seen in the visually interpreted EEGs of the chlor-alkali workers. Mellerio and Kubicki have described fast activity in the EEG at the outset of mercury intoxications. ${ }^{4}$ In more advanced cases slow rhythms together with paroxysmal activity have been seen. Besides a few case reports, no cross

Table 4 Absolute frequency powers, total powers, and amplitudes of the signal reflected by root mean square (RMS) for the exposed day and three-shift workers. (Derivation $O_{1}$ referenced to linked ears, eyes closed)

\begin{tabular}{lrrrrr}
\hline & \multicolumn{2}{c}{$\begin{array}{l}\text { Day workers } \\
(n=21)\end{array}$} & & \multicolumn{2}{c}{$\begin{array}{c}\text { Three-shift workers } \\
(n=20)\end{array}$} \\
\cline { 2 - 3 } \cline { 5 - 6 } EEG variable & Mean & $S D$ & & Mean & $S D$ \\
\hline Frequency (pW): & 12.8 & 4.3 & & 12.9 & 6.6 \\
Delta & 9.7 & 6.9 & & 7.6 & 3.7 \\
Theta & 44.9 & 37.7 & & 25.8 & 32.1 \\
Alpha & 9.6 & 6.8 & & 7.1 & 3.7 \\
Beta & 77.0 & 48.4 & & 53.5 & 41.1 \\
Total power (pW) & 8.4 & 2.6 & 6.9 & 2.5 \\
RMS $(\mu \mathrm{V})$ & & & & & \\
\hline
\end{tabular}

sectional or follow up studies have been publishe concerning EEG findings in workers exposed to vapour. Our data showed some similarities with earlier. reported findings, even though the present expose $\overline{\bar{G}}$ workers were considered as being without symptoms of $\mathrm{Hg}$ intoxications.

Of the subjects in our reference group, $15 \%$ showe EEG disturbances. This agreed well with the class $\overline{0}$ work of Gibbs and Gibbs ${ }^{12}$ : in their material of 1000 adults they found EEG abnormalities in about $15 \%$ of the subjects when slow and fast activity as well $\overrightarrow{a s}$ paroxysmal EEG abnormalities were included. Selec ted populations such as young male flight personnefs have shown an even lower number of EEG abnors malities-namely 7\% definitely abnormal and 5\% borderline or mildly abnormal. ${ }^{13}$ Although some of the EEG abnormalities reported in these studies arg nowadays considered as normal phenomena, ouro scaling of the EEG findings did not deviate apprecio bly from the interpretation of the others. Furthe? more, mild EEG abnormalities do not necessarily indicate brain disease. Functional changes may occut in the EEG due to, for example, metabolic and tox causes without structural brain damage.

In the cEEG the difference between the exposed an $\overline{\mathscr{Q}}$ the referents was most prominent in the recordings from the occipital area.The choice of the frontag parietal, and occipital areas for recording was made of the knowledge of the uneven accumulation of $\mathrm{Hg}$ i the brain cortex, which Takahata et al have shown if two necropsy cases with a history of $\mathrm{Hg}$ vapou intoxication. ${ }^{14}$ The changes in cEEG in the presen study were pronounced in the occipital areas and almost disappeared frontally, thus corresponding to the lower accumulation of $\mathrm{Hg}$ measured by Takahato et al.

The cEEG of the exposed workers showed slowing and attenuation of the power density spectra in comparison with the referents. In our study the shiftwork was an obvious confounding factor. Evein though special attention was paid to the standardisas tion of the timing of the examinations, the one hous earlier start of the workday as well as the strain due to changing workshifts might have caused more fatigu in the three-shift worker group, and thus decrease of their vigilance. The cEEG has been used as one of the best measures of vigilance. ${ }^{15}$ Indeed, the findings of the three-shift workers were clearly emphasised. Never theless, the overall attenuation of the cEEG remaine $q^{\circ}$ in the dayworker group. Besides, there was no reason to suspect a similar difference in vigilance between the dayworkers and the referents, which was the case among the three-shift workers.

Another confounding effect could have arisen fron exposure to methyl $\mathrm{Hg}$ from the general environment The brain has shown a special ability to accumulate 
both elementary $\mathrm{Hg}$ vapour and methyl $\mathrm{Hg} .{ }^{516} \mathrm{In}$ another forthcoming part of this present study it was shown that the magnitude of the organic $\mathrm{B} \mathrm{Hg}$ fraction of both exposed and reference subjects was connected to their consumption of fish. The most exposed chloralkali workers had lately restricted their fish meals to lessen their overall exposure, but among the exposed and the referent groups were subjects with a generous consumption of fish. Unfortunately, because no indicator of the methyl $\mathrm{Hg}$ dose in the brain caused by low long term exposure has been developed, the possible influence of additional exposure to methyl $\mathrm{Hg}$ on the cEEG could not be controlled in the study.

No suggestion of a dose effect relation was found in this study. The obvious explanation is that the concentrations of $\mathrm{B} \mathrm{Hg}$ or $\mathrm{U} \mathrm{Hg}$ and the concentrations of $\mathrm{Hg}$ in the brain do not correlate in general because they measure different temporal exposure..$^{1017}$

Based on the dose indicators applied in this study, the exposure level of both the chlor-alkali workers and the reference workers was low. Based on the ratio of concentrations of $\mathrm{Hg}$ in air and blood presented by Roels et al,$^{18}$ the long term average $\mathrm{Hg}$ concentration in air had probably been almost equal to WHO's health based recommended level of $25 \mu \mathrm{g} / \mathrm{m}^{3} .{ }^{17}$ This estimation, however, was not quite acccurate because of the short biological half time of inorganic $\mathrm{Hg}$ in blood. ${ }^{19}$ The estimation of the exposure level during the examinations was therefore more reliable. The dayworkers showed an average exposure of about $25 \mu \mathrm{g} / \mathrm{m}^{3}$ of air and the three-shift workers about $15 \mu \mathrm{g} / \mathrm{m}^{3}$ of air.

We conclude that the slowing and attentuation of the cEEG observed in the exposed workers was related to the low long term exposure to $\mathrm{Hg}$ vapour. The mental strain caused by shiftwork accentuated the disturbance in the EEGs. A longitudinal study design would be needed to verify these suggestive results. The computerised EEG could be developed into a methud for measuring early neurological effects of exposure to $\mathrm{Hg}$ vapour.

This study was supported by the Finnish Work Environment Fund.

\section{References}

1 Skerfving S, Vostal J. Symptoms and signs of intoxication. In: Friberg L, Vostal J, eds. Mercury in the environment. Cleveland: CRC Press, 1972:93-107.

2 Kark R. Clinical and neurochemical aspects of inorganic mercury intoxication. In: Vinken P, Bruyn G, eds. Handbook of clinical neurology. Vol 36. New York: Elsevier/North-Holland Biochemical Press, 1979:147-97.

3 Vroom FQ, Greer M. Mercury vapour intoxication. Brain 1972;95:305-18.

4 Mellerio F, Kubicki S. Encephalopathy due to poisoning. In: Remond A, ed. Handbook of EEG and clinical neurophysiology. Vol 15A. Amsterdam: Elsevier, 1977:108-35.

5 Berlin M. Mercury. In: Friberg L, Nordberg GF, Vouk VB, eds. Handbook on the toxicology of metals. Vol II. Amsterdam: Elsevier, 1986:387-445.

6 Herrmann WM. Electroencephalography in drug research. Stuttgart: Gustav Fischer, 1982.

7 Magos L, Cernik A. A rapid method for estimating mercury in undigested biological samples. Br J Ind Med 1969;26:144-9.

8 Lajunen L, Kinnunen A, Yrjänheikki E. Determination of mercury in blood and fish samples by cold-vapor atomic absorption and direct current plasma emission spectrometry. Atomic Spectroscopy 1985;6:49-52.

9 Chasson AL, Grady HT, Stanley MA. First order kinetic method. Am J Clin Pathol 1961;35:83-8.

10 Skerfving S, Berlin M. Oorganiskt kvicksilver. Nordiska expertgruppen för gränsvärdesdokumentation. Arbete och Hälsa 1985;20:1-77. (In Swedish with English summary.)

11 Tolonen U, Ahonen A. Relationship between regional pertechnetatic cerebral circulation time and EEG in patients with cerebral infarction. Electroencephalogr Clin Neurophysiol 1983;56:125-32.

12 Gibbs FA, Gibbs EL. Atlas of electroencephalography. Vol 1. Reading, Mass: Addison-Wesley Publishing Co 1958:106-12.

13 Maulsby RL, Kellaway P, Graham M, et al. The normative electroencephalografic data reference library. Final report, National Aeronautics and Space Administration, 1968. (Contract NAS 9-1200.)

14 Takahata N, Hayashi H, Watanabe B, Naso T. Accumulation of mercury in the brains of two autopsy cases with chronic inorganic mercury poisoning. Folio Psychiat Neurol Jap 1970;24:59-69.

15 Matousek M, Petersen I. A method for assessing alertness fluctuations from EEG spectra. Electroencephalogr Clin Neurophys 1982;55:108-13.

16 Magos L. Uptake of mercury by the brain. $B r J$ Ind Med 1968;25:315-8.

17 World Health Organisation Study Group. Recommended healthbased limits in occupational exposure to heavy metals. Geneva; WHO 1980. (WHO tech rep ser No 647.)

18 Roels H, Abdeladim S, Ceulemans E, Lauwerys R. Relationships between the concentrations of mercury in air and in blood or urine in workers exposed to mercury vapour. Ann Occup Hyg 1987;31:135-45.

19 Cherian MG, Hursch JB, Clarkson TW, Allen J. Radioactive mercury distribution in biological fluids and excretion in human subjects after inhalation of mercury vapor. Arch Environ Health 1978;33:109-14. 